\title{
MÚSICA E DISCIPLINA NA ESCOLA BRASILEIRA: ALGUNS APONTAMENTOS
}

\author{
Eliane Hilario da Silva Martinoff ${ }^{1}$ \\ Alexandre José de $\mathrm{Abreu}^{2}$ \\ Mônica Augusto ${ }^{3}$
}

Resumo: $\mathrm{O}$ presente artigo traz algumas ponderaçóes sobre a prática e o ensino musical no Brasil. Buscou-se refletir sobre alguns períodos da trajetória do ensino de música na escola brasileira a partir da chegada dos jesuítas até os dias atuais, com o intuito de compreender a situação atual, após o advento da lei 11.769, que estabelece a música como conteúdo obrigatório, mas não exclusivo no ensino de Arte. A fundamentação teórica está alicerçada em Foucault (2008) e a metodologia utilizada foi a pesquisa bibliográfica e documental. Concluiu-se que, mesmo não havendo no Brasil uma tradição de ensino interdisciplinar, especialmente na área de música, é preciso aprender com o passado e buscar práticas que considerem a cultura nacional, em suas diversas especificidades, bem como o conhecimento acumulado através dos tempos, visando a possibilidade de criação de novos conhecimentos na área.

Palavras-chave: Ensino de música. Funçôes da música. Interdisciplinaridade.

Música e poder.

\begin{abstract}
This article brings some weights on the practice and the musical education in Brazil. Sought to reflect on some periods of music education trajectory in brazilian school from the arrival of the Jesuits to the present day, in order to understand the current situation, after the advent of 11.769 law laying down the music as required, but not exclusive content in art education. The theoretical foundation is rooted in Foucault (2008) and the methodology used was bibliographical and documental research. It was concluded that, even in the absence of a tradition of interdisciplinary education in Brazil, especially in the music area, one must learn from the past and get practices that consider the national culture, in its various specificities, as well as the knowledge accumulated through the ages, aiming at the creation of new knowledge in the area.
\end{abstract}

Keywords: Music Education. Music functions. Interdisciplinary. Music and power.

\footnotetext{
1. Mestre e Doutoranda em Música pela Universidade Estadual Paulista Júlio de Mesquita Filho. Licenciada em Educação Artística com habilitação em Música e licenciada em Pedagogia, atualmente é Professora da Universidade Municipal de São Caetano do Sul (USCS). e-mail: elmartinoff@uscs.edu.br

2. Mestre e Doutorando em Música. Músico da Orquestra Sinfônica da Unicamp e professor da escola livre da Universidade Estadual de Campinas (UNICAMP) e-mail: alexandreabreu20@hotmail.com

3. Bacharel em Música e em Direito. Atualmente é graduanda em Filosofia pela Fapcom - Faculdade Paulus de Tecnologia e Comunicação.
} 


\section{INTRODUÇÃO}

A Lei de Diretrizes e Bases da Educação Nacional 9394/96 estabelece a arte como "componente curricular obrigatório nos diversos níveis da educação básica” (Art. 26, \$2º, BRASIL, 1996). Em 2008, teve seu texto alterado por meio da lei ordinária 11.769, que tornou obrigatória a presença de conteúdos de música no ensino de Arte na educação básica brasileira.

Desde que essa lei foi sancionada, vários questionamentos vem sendo levantados. Um deles, e que preocupa os educadores é se os conteúdos de música passam a ser obrigatórios, mas não exclusivos, a lei reconhece a música apenas como um dos componentes da Arte e náo como disciplina? Se a música náo é vista como disciplina, mas um componente de uma área, isso pode ser visto como uma questão interdisciplinar?

Assim, no contexto atual, após a aprovação da Lei 11769/08, torna-se urgente refletir mais profundamente sobre a função da música na educação básica. Para que se possa compreender como se chegou ao estado atual, é importante conhecer os fatores que determinaram historicamente essa situação. Dessa forma, um olhar mais detalhado permite perceber que as transformaçôes de um saber que se torna escolar não obedece a uma linearidade lógica, mas deriva de uma série de imposiçôes que resultam em variaçôes características e específicas em cada espaço social e em cada época. Essas variaçôes podem ser mais bem compreendidas se observarmos que a sociedade traz demandas sobre a escola, que variam de acordo com as mudanças ocorridas na própria sociedade.

Para nos auxiliar, então, nessa reflexão, lançamos um olhar sobre alguns períodos da história da educação brasileira, na busca de exemplos que nos subsidiem nessas ponderaçôes.

\section{A MÚSICA E SEU ENSINO NO BRASIL COLONIAL}

Desde a chegada ao Brasil em 1549, os jesuítas atuaram nas aldeias indígenas utilizando a música como meio de aproximação com os índios. Segundo Marcos Holler (2010, p. 159), essa utilização estendeu-se até o momento da expulsão em 1759.

Em sua carta a El Rey Dom Manuel, ao aludir à celebraçáo da missa realizada no domingo de Páscoa, Caminha relata que os índios "olhando-nos, sentaram-se. E, depois de acabada a missa, assentados nós à pregação, levantaram-se muitos deles, tangeram corno ou buzina, e começaram a saltar e dançar um pedaço”. E Jean de Léry, aqui chegado em 1557, ao relatar suas impressões sobre a música praticada pelos índios afirma que "essas cerimônias duraram cerca de duas horas e durante esse tempo os quinhentos ou seiscentos selvagens não cessaram de dançar e cantar de um modo tão harmonioso que ninguém diria não conhecerem música” (LÉRY, 1972, p. 164). 
A reação dos jesuítas a essa música, porém, foi bem diferente. $\mathrm{O}$ crítico musical e historiador José Ramos Tinhorão, faz referência a uma carta escrita pelo Padre Manuel da Nóbrega, em 1549, dirigida ao Padre Simão Rodrigues, na qual menciona que seu colega Aspilcueta Navarro visitava "ora um, ora outro lugar da cidade e à noite ainda faz cantar os meninos certas oraçóes que lhes ensinou em sua língua deles, em lugar de certas cançôes lascivas e diabólicas que antes usavam”. E esclarece que

A impressão definida como diabólica das cançôes indígenas derivava, naturalmente, da forma pela qual os padres as ouviam, sempre ligadas a danças rituais, entre batidas de pés no chão, volteios de corpo e pequenos estribilhos em uníssono, pois - como informava o padre Fernão Cardim falando de "bailos e canto" dos índios - não fazem uma coisa sem a outra (TINHORÃO, 1972, p. 10, aspas do autor).

$\mathrm{Na}$ Companhia de Jesus havia uma regra que estabelecia jesuita non cantat. Muitas são as explicaçóes para a existência dessa regra e vários mitos teriam sido criados. Holler (2010, p. 141) esclarece que as restriçôes ao uso da música tinham um fundo prático. Quando da sua criação, a Companhia de Jesus foi direcionada a privilegiar o que chamavam de cuidado dos bens espirituais, que consistia em atividades como a catequese, a pregação, ministrar os sacramentos e atuar junto ao povo através da educação e das obras assistenciais. Para Loyola - fundador da Companhia de Jesus -, a música absorveria os padres, tirando-os do trabalho cotidiano.

Embora a proibição da música tenha sido exercida com mais rigor na Europa (e realmente seguida até 1555), seu uso na propagação da fé e nos Colégios estabelecidos nas Índias e no Novo Mundo era, na verdade, incentivado.

Assim, na América Portuguesa e, mais especificamente no Brasil, as dificuldades enfrentadas no campo missionário imprimiram mudanças no projeto de conversão e, por isso, a adaptabilidade jesuítica foi fundamental para sua longevidade entre os índios da América; apesar dessa postura antimusical dentro da Companhia de Jesus, com o tempo desenvolveu-se uma tradição musical nas igrejas e colégios jesuíticos. Antes e depois da morte de Loyola, documentos revelam que missas eram cantadas pelos missionários ao redor do mundo. (WITTMANN, 2011, p. 47).

Assim, dentro do princípio de que era preciso ser todas as coisas para todos os homens a fim de conquistá-los, os jesuítas "tornaram-se os primeiros professores de música do Brasil” e a música foi um dos elementos importantes na prática de ensino (TINHORÃO, 1972, p. 10).

Ainda no período colonial, a música praticada no Brasil começou a apresentar sinais de secularização. Uma das causas importantes foi a descoberta de ouro e pedras preciosas nas Capitanias das Minas Gerais, no século XVII, o que imprimiu um novo caráter à cultura brasileira. A vinda de escravos de outras regióes do Brasil ou de indígenas trazidos pelos bandeirantes, não poderia por si só solucionar o problema da falta de mão de obra, o que acarretou uma intensificação do tráfico de escravos africanos. O sociólogo e poeta Valter Krausche observa que 
$\mathrm{O}$ aprendizado de um certo instrumento musical aumentava o preço do escravo, o que era interessante ao seu senhor; ao mesmo tempo, garantia ao escravo um certo "tempo livre”, um afrouxamento de sua escravidão. Ele obrigatoriamente se abre e enxerga outros agrupamentos sociais; sua música não é para si mesmo, mas também para outros, e o seu espaço social de criatividade se transforma (KRAUSCHE, 1983, p. 19).

Segundo Souza e Lima (2007, p. 33, 43, 61), na América portuguesa, a música era componente fundamental do trabalho cotidiano dos negros, além de estar sempre presente em danças e rituais. "Como práticas coletivas, muitos historiadores analisam-nas não como atos desinteressados da parte dos homens de cor livres ou escravos, mas como constituintes da disputa cultural e política” que envolvia, sobretudo, europeus brancos, de um lado, e africanos e mestiços, de outro. Entretanto, a outra face da expressão cultural de homens de cor por meio da música "sequer implicava resistência. Ao contrário, milhares de pardos, pretos e mulatos ${ }^{4}$ dedicaram-se intensamente ao estudo, ensino, produção e reprodução de música erudita no Brasil colonial”. Dessa forma, o talento musical permitiu que pardos e mulatos transitassem entre seu mundo social - marcado pelas limitaçóes atribuídas à cor - e o mundo dos brancos. Como professores de música, por exemplo, seus serviços eram contratados por membros das elites. Gilberto Freyre (1999) comenta que

Os pretos foram os músicos da época colonial e do tempo do Império. Os moleques, meninos de coro nas igrejas. Várias capelas de engenho tiveram coros de negros; várias casas-grandes, conservando a tradição de Mangue la Bote, mantiveram, para deleite dos brancos, bandas de música de escravos africanos. (FREYRE, 1999, p.417).

Vemos, então, que o exercício da música e o seu ensino contribuíam para o livre trânsito entre as classes sociais.

Em 1759 foi editado o decreto do Marquês de Pombal, Sebastião de Carvalho e Mello, expulsando os jesuítas de Portugal e seus domínios. Com o banimento dos inacianos desmantelou-se toda uma estrutura administrativa de ensino. A uniformidade da açáo pedagógica, a perfeita transição de um nível escolar para outro, a graduação, foram substituídas pela diversificação das disciplinas isoladas. Foram então instituídas as chamadas aulas-régias, que se constituíam em unidades de ensino, com professor único, para determinada disciplina. Eram autônomas e isoladas, não se articulando a outras disciplinas, nem pertencendo a qualquer escola. Não havia currículo e o aluno se matriculava em quantas aulas ou disciplinas desejasse. Essas aulas apesar de incorporarem disciplinas compatíveis com o momento histórico, preservaram as marcas da tradição jesuítica. Dessa forma, nelas a música continuava presente, com forte conotação religiosa, muito ligada às características e formas europeias, conotação esta que se fez evidente em toda a produção musical do período colonial.

4. "Mulato" era um termo pejorativo ligado ao escravo mestiço, enquanto "pardo" mais do que óbvia cor da pele, era subentendido como condição social de um indivíduo livre. Tanto que as denominações ligadas às irmandades devocionais de mestiços livres se autodenominavam "pardos" e não "mulatos". (LEONI, 2010, p. 102, aspas do autor). 


\section{ENSINO MUSICAL NÃO FORIMAL NO BRASIL NO SÉCULO XIX}

A chegada da Corte em 1808 estimulou o desenvolvimento de um processo de modernização, pois, naquele momento, o Brasil não era mais uma simples colônia e sim, sede da monarquia portuguesa. Nesse processo, o campo musical foi um dos alvos privilegiados pelas mudanças, que se materializaram através da criação da Casa da Ópera e da Capela Real, ambas destinadas à execução de música erudita, sendo aquela reservada à profana e esta à sacra.

Durante o século XIX, no Brasil, dezenas de bandas de música foram organizadas especialmente na cidade de Campinas, no interior paulista, pois a sociedade como um todo se via representada em bandas de comerciantes, operários, escravos de fazendas, amadores, alunos de escolas e imigrantes (italianos, alemães e portugueses). O auge da lavoura cafeeira dava o suporte econômico para este acréscimo na atividade musical que teria certa relaçáo com o espírito da época, que via na atividade musical das bandas um ócio edificante e moralizante.

A atuação destas instituições foi fundamental para a constituição do panorama cultural que a cidade vivenciou, de um lado difundindo a prática de um repertório específico (marchas, valsas, hinos, adaptaçốes de aberturas de óperas) que iria embasar a construçáo de gosto comum 5 e, de outro lado, contribuindo para a formação de inúmeros instrumentistas. $\mathrm{Na}$ ausência de instituiçóes oficiais que tomassem a iniciativa do ensino de música, esta tarefa seria, no período tratado, realizada de uma forma direta, onde figuras como o mestre de música e de banda seriam ainda as únicas referências possíveis.

A relação entre uma banda de música e uma escola no período tratado deixa entrever aspectos importantes da circulação de cultura em uma sociedade, mas, igualmente, possui certa conveniência de meios e fins, proposiçôes de construção, ou no caso, celebração de uma nacionalidade. Coincidência ou não, instituições coletivas de ensino, a formatação dos discursos nacionais ${ }^{6}$ e o desenvolvimento das bandas de música são fatos que dividem uma mesma periodização. Na realidade, um olhar mais atento para estes elementos inicialmente distintos, pode apontar para um, se náo necessário, ao menos, possível fator de confluência.

Importante para análises contextuais neste período é o trabalho de Foucault ao analisar as instituições disciplinares ${ }^{7}$ e suas funçóes dentro do quadro de dinâmicas de poder. Para o epistemólogo francês, as instituiçóes disciplinares que entram em cena durante o século XVIII a meados do século XIX, são dispositivos organizacionais que são levados a cabo para dirimir os problemas relacionados ao grande contingente populacional ao mesmo passo em que atualizam a transição de um sistema político baseado na soberania para outro que legitime os estados nacionais.

5. Nogueira (2001) nos apresenta o fato que em uma destas comemorações a banda Luiz de Camões realiza uma apresentação de um trecho operístico (I Puritani) dentro de uma igreja, o que nos faz refletir sobre o peso deste 'gosto' comum que ignora as barreiras tradicionais.

6. Na forma explicita por Benedict Anderson, ou seja, de discursos imaginados (ANDERSON, 2008).

7. 0 termo disciplina, no seu uso escolar, tem designado também a repressão das condutas prejudiciais à boa ordem. 
A disciplina é uma técnica de exercício de poder que foi, não inteiramente, inventada em seus princípios fundamentais durante o século XVIII. Historicamente as disciplinas existiam há muito tempo, na Idade Média e mesmo na antiguidade. Os mosteiros sâo um exemplo de região, domínio no interior do qual reinava o sistema disciplinar. A escravidão e as grandes empresas escravistas existentes nas colônias espanholas, inglesas, francesas, holandesas, etc., eram modelos de mecanismos disciplinares. Podese recuar até a Legião Romana e, lá, também encontrar um modelo de disciplina. Os mecanismos disciplinares são, portanto, antigos, mas existiam em estado isolado, fragmentado, até os séculos XVII e XVIII quando o poder disciplinar foi aperfeiçoado como uma nova técnica de gestão dos homens. Fala-se, frequentemente, das invençôes técnicas do século XVIII - as tecnologias química, metalúrgicas, etc. - mas, erroneamente, nada se diz da invençáo técnica dessa nova maneira de gerir homens, controlar suas multiplicidades utilizá-las ao máximo e majorar o efeito útil de seu trabalho e sua atividade, graças a um poder suscetível de controlá-los. Nas grandes oficinas que começam a se formar, no exército, na escola, quando se observa um grande progresso da alfabetização, aparecem essas novas técnicas de poder que são uma das grandes invençôes do século XVIII (FOUCAULT, 2008, p. 105).

Anderson (2008) colabora neste sentido quando nos apresenta o caráter imaginário da construção da nacionalidade, explicitamente relacionado à legitimação dos estados nacionais, neste período. Sem bases possíveis, as instituiçôes culturais são conclamadas a tomar partido nesta celebração do nacional. $\mathrm{E}$ as mesmas bandas que outrora celebravam o 'Rei' agora são chamadas a celebrar o estado8; muito embora nem todos concordem com o 'Rei' todos o aguardam quando a banda soa e a sociedade em sua diversidade esconde os vários níveis de divergência sob um manto elaborado de aceitação quanto ao sistema e seus símbolos.

Necessária para a efetiva validação dos discursos nacionais, tratados por Anderson, a disciplina que Foulcault apresenta se caracteriza pelo exercício sobre os corpos sob um ambiente panóptico9, isto é, um ambiente onde os indivíduos possam ser vigiados, controlados, classificados e, sobretudo, submetidos à disciplina, conforme ilustrado na figura1.

\footnotetext{
8. Some-se a isto o fato de que em meio à estes conclaves entre nacionalidades o Brasil no período ainda se estabelece enquanto monarquia, 0 que longe de desclassificá-lo frente ao problema parece, inclusive, imprimir-lhe mais força.

9. Estrutura proposta por Jeremy Bentham (1748 - 1832) composta por uma torre central cercada por um anel de pequenas salas, onde 0 vigilante na torre teria 0 total controle das pessoas dispostas nas mesmas (ABREU, 2010).
} 
Figura 1. Penitenciária de Stateville (EUA), o panóptico de Jeremy Bentham (1748-1832) como modelo para instituiçóes disciplinares.

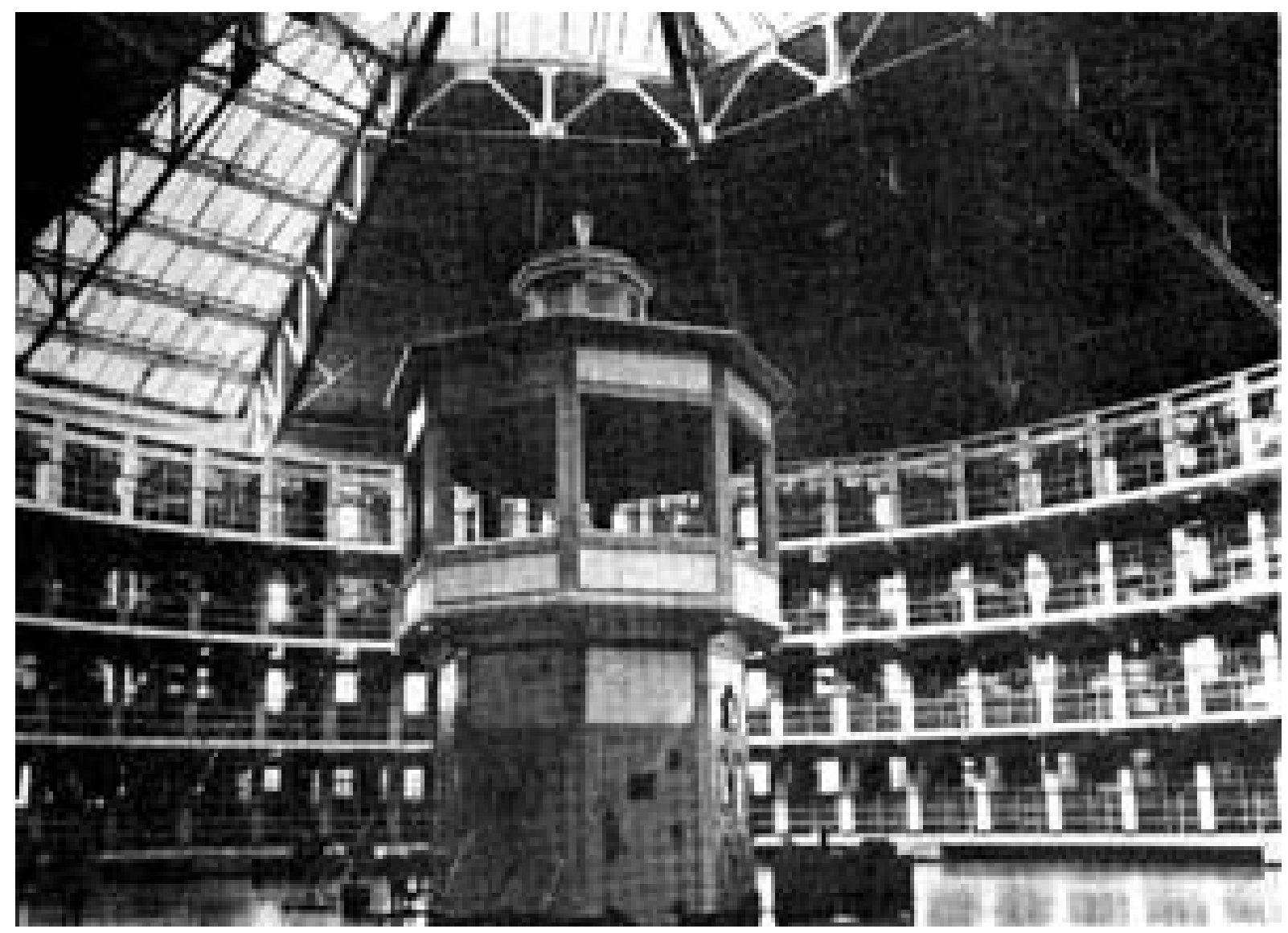

Fonte: Cordeiro (2005).

Atuando sobre a lógica dupla de instituiçôes formativas e dispersoras, as bandas de música tiveram papel importante na construção disciplinar, do ponto que nos fala Foucault. Estruturas estruturantes formaram, por um lado músicos hábeis e familiarizados com um repertório e práticas específicas e, por outro, um público receptivo para o consumo deste mesmo repertório e práticas.

De um modo circular, a disciplina de Foucault envolve tanto músicos como público sob um mesmo ambiente de práticas e 'gosto', desenvolvendo em alguns, habilidades determinadas e verificáveis, ao passo que, em outros, o desejo, a expectativa de consumo destas mesmas práticas. A disciplina reúne a prática e a recepção sob um único contexto de atualização, indivisível e irredutível ao valor unitário de seus segmentos, verificáveis, contudo, através das trocas simbólicas realizadas por estes.

Neste sentido, relacionar a atividade das bandas de música com a rotina e disciplina escolar revela muito mais do que apenas uma conveniência de propósitos; as próprias práticas envolvidas teriam um sentido moralizante e educativo, um papel civilizatório que a atividade junto a uma banda de música deveria embasar: não apenas formar bons músicos e plateias atentas, como bons cidadáos, atentos e seguros da importância e significação da nacionalidade e seus símbolos. 
A relação entre colégios e bandas durante o período expressa a preocupação presente no mesmo quanto à forma de lidar com os grandes contingentes populacionais; educar as massas de forma eficiente é um dado importante e ambas as instituições se inserem neste contexto. Enquanto a escola teria a função de educar, caberia à banda uma atribuição paralela: familiarizar as pessoas com um 'gosto’ específico e moralizante. Sendo assim, as duas instituições desempenhariam funçóes agregadas.

Uma vez reunidas sob uma mesma instituição, como neste caso, poderíamos analisar a instituição sob seu aspecto disciplinar, à maneira de Foucault, e atentarmos para o modo com que organiza e dispóe os indivíduos de uma coletividade, confirmando, igualmente, os valores que os destacam enquanto segmentos sociais. $\mathrm{O}$ culto às nacionalidades, ao discurso nacional, entra neste ponto, como moralizante e distintivo, associando à pratica musical valores extramusicais e simbólicos.

\section{ENSINO DE MUÚSICA NO SÉCULO XX}

Em 1930, o presidente Getúlio Vargas criou o Ministério da Educação e Saúde Pública, indicando Francisco Campos para essa pasta. No primeiro semestre de 1931, o novo ministro baixou um conjunto de decretos, que ficou conhecido como a Reforma Francisco Campos, entre os quais o de número 19.890, de 18 de abril de 1931, que dispunha sobre a organização do ensino secundário. Foi por meio desse decreto que o Canto Orfeônico se tornou obrigatório nas escolas públicas do Rio de Janeiro, nos três primeiros anos do curso fundamental (capítulo I, art. $3^{\circ}$ ) e foi ajustado posteriormente em alguns aspectos pelo de número 21.241, de 4 de abril de 1932.

Segundo Pessanha; Daniel e Menegazzo (2004, p. 60), é possível perceber na história da disciplina Canto Orfeônico, "traços de uma sociedade que tinha a ordem e a disciplina como valores, pelo menos entre as fraçóes de classe que a dirigiam". Esses valores deveriam ser preservados e cultivados tanto na formação dos professores quanto nas disciplinas escolares,

Provavelmente para se contrapor à "desordem" e à "anarquia" dos anos loucos, dos anos de 1920, quando foi possível o surgimento de movimentos anarquistas, comunistas e modernistas, cabia agora "oficializar", "normalizar", "rotinizar", ou reprimir sumariamente, para que nada saísse dos trilhos, para usar uma metáfora bem cara à época: a de que a sociedade devia "entrar nos trilhos" do progresso como as locomotivas (PESSANHA, DANIEL; MENEGAZZO, 2004, p. 60).

Visando a divulgação do canto coletivo nas escolas brasileiras deixou-se de lado, na fase inicial do projeto, a formação de profissionais bem qualificados, já que foi necessário formar professores para a prática musical de modo emergencial, uma vez que não havia número suficiente de docentes dessa disciplina para atender às escolas públicas e nem as Escolas Normais. 
A criação da disciplina canto orfeônico, considerada explicitamente uma disciplina estratégica, sob a inspiração e regência de Villa-Lobos, teve como objetivo realizar com a música o que as tropas não haviam conseguido: unir multidóes de brasileiros cantando a uma só voz, seguindo as instruçôes de um maestro. (PESSANHA; DANIEL; MENEGAZZO, 2004, p. 60, itálico das autoras).

Por meio do canto todos teriam a possibilidade de experimentar a coletividade sem que com isso se perdesse a personalidade livre do indivíduo, podendo assim se preocupar com interesses humanos de maneira geral. $\mathrm{Na}$ escola, a música era elemento importante para forjar comportamentos e disciplinar a conduta dos alunos.

\subsection{ENSINO DE MÚSICA NO BRASIL NO PERÍODO DA DITADU- RA MILITAR}

Em 1964, com a tomada do poder pelos militares adotou-se uma série de medidas para prover o regime de meios necessários para que pudesse se manter, pois a sociedade mesmo tendo apoiado o Golpe, começou a questionar o poder instituído nos anos que se seguiram, fruto das atitudes arbitrárias dos chefes militares.

O período de 1964 a 1971 foi marcado por profundas e significativas mudanças históricas, que envolveram a Revolução de 64 e o período de industrialização, o qual necessitava de pessoas para atuarem no mercado de trabalho, que soubessem ler e escrever para poderem manusear máquinas industriais. A educação não ficou imune a todas essas mudanças, pois, como acontece em todos os regimes autoritários, "a escola foi alvo de atenção especial, em virtude de seu importante papel no campo da divulgação ideológica" (MARTINOFF, 2013). Foi com esse pano de fundo que o governo estruturou e aprovou as reformas educacionais, sendo elas a Reforma do Ensino Superior, ou Reforma Universitária, como ficou conhecida (Lei 5540/68) e a Reforma do $1^{\circ}$ e $2^{\circ}$ graus (5692/71).

As principais mudanças na escola básica aconteceram a partir da promulgação da Lei 5.692/71 e implicaram a unificação do ensino primário, de $1^{\text {a }}$ a $4^{\mathrm{a}}$ séries, com o ensino ginasial, também de $1^{\mathrm{a}}$ a $4^{\mathrm{a}}$ séries, eliminando-se o exame de admissão, que selecionava os ingressantes para esta segunda fase. A partir de entáo, criou-se o ensino de $1^{\circ}$ grau, com oito séries, com finalidade profissionalizante nos locais onde os alunos majoritariamente encerrassem sua vida escolar nesse nível. Onde houvesse condiçóes de prolongamento dos estudos até o $2^{\circ}$ grau, este teria a missão da profissionalização.

Um dos possíveis efeitos da nova legislação foi o crescimento do número de matrículas, em todas as séries. Acompanhando tal aumento, houve uma expansão da rede física da escola, que se expressou tanto na construção de novos prédios para abrigar grande número de ingressan- 
tes, como na ampliação do número de salas nas unidades existentes, além do funcionamento da escola em três turnos.

O currículo também sofreu modificaçóes, aglutinando disciplinas, como História e Geografia para dar lugar aos Estudos Sociais, além das modalidades artísticas (Artes Visuais, Música, Teatro e Desenho, substituído mais tarde pela Dança), que se juntaram numa única disciplina: Educação Artística. Surgiu também a Educação Moral e Cívica no primeiro grau (hoje ensino fundamental), Organização Social e Política do Brasil, no ensino secundário (hoje ensino médio) e Estudos de Problemas Brasileiros no ensino superior.

Segundo o historiador norte-americano, especializado em História do Brasil, Thomas Skidmore (1988), tornou-se necessário naquele momento, adequar todas as instâncias nacionais aos interesses da nova classe no poder, para que o Regime Militar pudesse ser legitimado e não correr o risco de ser deposto. Nesta perspectiva, foi criado um aparato governamental que restringia os direitos civis e políticos da população a fim de calar todas as possíveis vozes de contestação ao regime. Assim,

pautado pela repressáo, o Estado editou políticas e práticas que, em linhas gerais, redundaram no tecnicismo e na expansão quantitativa da escola pública de $1^{\circ}$ e $2^{\circ}$ graus à custa do rebaixamento da sua qualidade e também no cerceamento e controle das atividades acadêmicas no interior das universidades e da expansão da iniciativa privada no ensino superior (FERREIRA JÚNIOR ; BITTAR, 2006, p.1161).

Para a coordenadora do Programa de Pós-graduação em Educação da PUC de São Paulo, Míriam Jorge Warde, essa legislação trouxe à tona a estrutura da escola brasileira: "instituição a serviço da reprodução da divisão do trabalho intelectual/trabalho manual ou, o que quer dizer instituição a serviço da reprodução das relaçôes de exploração e dominação” (WARDE, 1977, p. 89).

Deve-se destacar que, em 1977, Warde ainda não faz referência ao termo "tecnicismo". Esse termo é utilizado por Saviani (1982) ao analisar a Lei 5692/71, em face às Leis 4024/61 e 5540/68, quando afirma que "a inspiração liberalista que caracterizava a Lei 4024/61 cede lugar a uma tendência tecnicista nas Leis 5540/68 e 5692/71” e destaca que:

enquanto o liberalismo póe a ênfase na qualidade ao invés da quantidade; nos fins (ideais) em detrimento dos métodos (técnicas); na autonomia versus adaptação; nas aspiraçôes individuais ao invés das necessidades sociais; e na cultura geral em detrimento da formação profissional, com o tecnicismo ocorre o inverso. Ora, enquanto os princípios da Lei 4024 acentuavam o primeiro elemento dos pares de conceitos acima enunciados, os princípios das Leis 5540 e 5692 inegavelmente fazem a balança pender para o segundo (SAVIANI, 1982, p.148). 
Quanto à música, conforme dito anteriormente, pela Lei 5.692/71, passou a ser incluída no currículo escolar juntamente com outras práticas, com o nome de Educação Artística, porém não como disciplina. Sabemos que o início dos estudos sobre interdisciplinaridade no Brasil se deu na década de 1960 (FAZENDA, 1994), porém é possível que tenha havido uma confusão entre o conceito de interdisciplinaridade e o de multidisciplinaridade, que vem a ser a justaposição de disciplinas, onde cada uma trata de temas comuns sob sua própria ótica.

A disciplina Educação Artística surgiu no Brasil no mesmo momento em que as propostas criativas de compositores voltados para a questão da educação musical estavam fazendo chegar às escolas europeias e norte-americanas a música do seu próprio tempo. Fonterrada aponta que

$\mathrm{Na}$ escola brasileira, arrochada pelo regime militar, a arte embora chamada de "espaço de liberdade", perdia seu lugar entre as disciplinas curriculares, caracterizando-se como "ornamento para festas" ou diversão. O discurso libertário que cercou a implantação da educação artística falava de criação, sensibilização e liberdade de escolha, em profundo contraste com o regime forte militar que governava o Brasil, que não poupava represálias à expressão de opinióes (FONTERRADA, 2008, p. 340-341, aspas da autora).

Sabemos que a educação se apresenta como importante espaço de tensôes políticas por envolver dimensóes ideológicas e econômicas geradoras de poder. A formação escolar capaz de conferir aos trabalhadores as condições necessárias para que ocupem posição central no cenário político e compreendam e desfrutem o patrimônio cultural produzido pela humanidade se assenta em um propósito educacional profissionalizante que considera igualmente importantes a cultura geral (como literatura, música e artes visuais), a formação política e a capacitação técnica. Machado (in FOUCAULT, 2008, p XIII) esclarece que, para Foucault, é necessário

[...] partir da especificidade da questão colocada, que [...] é a dos mecanismos e técnicas infinitesimais de poder que estão intimamente relacionados, como a produção de determinados saberes - sobre o criminoso, a sexualidade, a doença, a loucura, etc. - e analisar como esses micropoderes, que possuem tecnologia e história específicas, se relacionam com o nível mais geral do poder constituído pelos aparelhos do estado.

Para Martinoff (2013), no período militar as transformações na escola se deram até nas mudanças que ocorreram em função da vigilância que os professores sentiam ao exercer sua profissão. A despeito de não haver uma repressão mais direta às escolas básicas, como havia às universidades, os docentes da escola básica também se percebiam vigiados. Lourenço (2010) comenta que todos os docentes no período, sabiam que o não cumprimento das ordens levava à prisão. Em um regime de exceção, que se instalou a partir do AI-5, qualquer descuido poderia ser fatal. Dessa forma, percebe-se que as normas foram internalizadas e o próprio sistema escolar, e os que dele participaram, se encarregaram da fiscalização. 


\subsection{ENSINO DE MÚSICA NA ATUALIDADE}

A LDB 9.394/96 estabeleceu a Arte como disciplina obrigatória. Embora os Parâmetros Curriculares Nacionais (PCN) trouxessem orientaçóes concernentes ao trabalho com as quatro linguagens - Artes Visuais, Música, Teatro e Dança - não havia uma orientação clara quanto à presença de cada uma delas, isto é, as modalidades artísticas poderiam, por exemplo, ser abordadas de forma intercalada em anos diferentes. Assim, em 2008 a lei 11.769 estabeleceu que conteúdos de música estivessem presentes de maneira imperativa no ensino de Arte em toda a educação básica.

Em 2013, o artigo 26 da LDB teve seu texto alterado pela Lei 12.796, estabelecendo que

[...] os currículos da educação infantil, do ensino fundamental e do ensino médio devem ter base nacional comum, a ser complementada, em cada sistema de ensino e em cada estabelecimento escolar, por uma parte diversificada, exigida pelas características regionais e locais da sociedade, da cultura, da economia e dos educandos (BRASIL, 2013, art. 26).

Em julho de 2015, depois da composição da comissão de especialistas que trabalhariam na elaboração da Base Nacional Comum Curricular (BNCC) e do lançamento do portal da Base na Internet, foi apresentado o texto preliminar. Em setembro desse mesmo ano, o site foi aberto à consulta pública e sugestôes e críticas puderam ser enviadas até março de 2016, a partir das quais foi lançada uma segunda versão do documento em maio desse ano. Desde então, foram marcados vários seminários para discussão do assunto.

A primeira versão do documento tinha 302 páginas e a segunda, aumentando consideravelmente sua extensão, 676, apresenta muitos objetivos de aprendizagem em alguns componentes curriculares. Quanto ao ensino de Arte, na primeira versão considera-se que "na Educação Básica, a Arte se caracteriza por trabalhar com o processo criativo em seus diferentes subcomponentes, englobando o fazer, o fruir e a reflexão sobre o fazer e o fruir" (BRASIL, 2015, p. 82). No campo específico da música, é estabelecido que:

O processo pedagógico em música está relacionado à mobilização, transmissão e apropriação de conhecimentos adquiridos por meio do exercício de práticas musicais sensoriais, analíticas e discursivas diversificadas, tendo como princípios fundamentais o fruir, o refletir e o fazer música, desenvolvendo o pensamento crítico e a criatividade. As bases epistemológicas do conhecimento em música se constituem na relação entre aspectos da Educação Musical e de outros campos do saber, que possibilitam a compreensão musical do sujeito, no que se refere à sua relação consigo mesmo, com o outro, com a sociedade e com a própria música (BRASIL, 2015, p. 83-4). 
Como se observa, a prioridade é a criatividade e a fruição, o que denota certa continuidade das práticas apontadas como prioritárias e necessárias no ensino de música no período da ditadura militar...

\section{CONSIDERAÇÕES FINAIS}

Vimos que, historicamente, não temos no Brasil uma tradição de ensino interdisciplinar, especialmente na área de música. Atualmente, com a busca de novos rumos para o ensino de música, após o advento da lei 11769/08, precisamos considerar a possibilidade de aprendermos a pensar e ensinar interdisciplinarmente.

Lima observa que um professor acostumado à prática interdisciplinar, passa a identificar aspectos próprios do conhecimento do homem e procura vivenciar "a possibilidade de se deixar conduzir por outras dimensôes que não apenas as concretas, ou racionais, privilegiando aspectos subjetivos do conhecimento humano" (LIMA, 2007, p. 61).

Por isso, é preciso aprendermos com o passado e buscarmos práticas que considerem a cultura nacional, em suas diversas especificidades, bem como o conhecimento acumulado através dos tempos, visando a possibilidade de criação de novos conhecimentos na área.

\section{REFERÊNCIAS BIBLIOGRÁFICAS}

ABREU, Alexandre José de. José Pedro de Sant'Anna Gomes e a atividade das bandas de música na Campinas do século XIX. Dissertação (Mestrado em Música), Instituto de Artes, Unicamp, Campinas, 2010.

ANDERSON, Benedict. Comunidades imaginadas. São Paulo: Companhia das Letras, 2008.

BRASIL. Decreto no 19.890 de 18 de abril de 1931. Dispóe sobre a organizaçáo do ensino secundário. Disponível em <http:/www.histedbr.fe.unicamp.br/navegando/fontes_escritas/5_Gov_Vargas/decreto\%20 19.890-\%201931\%20reforma\%20francisco\%20campos.htm>. Acesso em: 01 nov. 2015.

Lei No. 9.394, de 20 de dezembro de 1996. Brasília: Ministério da Educação, 1996.

2013. Lei 12.796, de 4 de abril de 2013. Altera a Lei no 9.394, de 20 de dezembro de 1996, que estabelece as diretrizes e bases da educação nacional, para dispor sobre a formação dos profissionais da educação e dar outras providências. Disponível em < http://www.planalto.gov.br/ccivil_03/_ato20112014/2013/lei/l12796.htm>. Acesso: 29 set. 2016.

BASE NACIONAL COMUM CURRICULAR. Ministério da Educação. Brasília, 2015. Disponível em <http://undime-sc.org.br/wp-content/uploads/2015/09/BNCC-APRESENTACAO.pdf>. Acesso: 11 set. 2016. 
CORDEIRO, Suzann. Arquitetura penitenciária: a evolução do espaço inimigo. Arquitextos, 059.11, ano 05, abr. 2005. Disponível em < http://www.vitruvius.com.br/revistas/read/arquitextos/05.059/480>. Acesso: 07 out. 2016.

FAZENDA, Ivani. Interdisciplinaridade: História, teoria e pesquisa. Campinas, SP: Papirus, 1994.

FERREIRA JR., Amarilio; BITTAR, Marisa. A ditadura militar e a proletarização dos professores. Educ. Soc., Campinas, vol. 27, n. 97, p. 1159-1179, set./dez. 2006. Disponível em <http://www.cedes.unicamp. br>. Acesso em 12/07/2012.

FONTERRADA, Marisa Tench de Oliveira. De tramas e fios. Um ensaio sobre música e educação. 2. ed. São Paulo: Editora UNESP; Rio de Janeiro: Funarte, 2008.

FOUCAULT, Michel. Microfísica do poder. Organização e tradução de Roberto Machado. Rio de Janeiro: Graal Editora, 2008.

FREYRE, Gilberto. Casa Grande \& Senzala: formação da família brasileira sob o regime da economia patriarcal. 35 ed. Rio de Janeiro: Record, 1999.

HOLLER, Marcos. Os jesuítas e a música no Brasil colonial. Campinas, SP: Editora Unicamp, 2010.

KRAUSCHE, Valter. Música popular brasileira. São Paulo: Brasiliense, 1983.

LEONI, Aldo Luiz. Historiografia musical e hibridação racial. Revista Brasileira de Música. Universidade Federal do Rio de Janeiro, v. 23/2, 2010, p. 95-119.

LÉRY, Jean de. Viagem à terra do Brasil. Tradução e notas de Sérgio Milliet. S. Paulo: Martins, Ed. Da Universidade de São Paulo, 1972.

LIMA, Sonia Albano de. Interdisciplinaridade: uma prioridade para o ensino musical. Música Hodie, vol. 7, no 1. Goiânia: UFG, 2007, p 51-65.

LOURENÇO, Elaine. O ensino de História encontra seu passado: memórias da atuação docente durante a ditadura civil-militar. Revista Brasileira de História. São Paulo, v. 30, no 60, p.97-120, 2010.

MARTINOFF, Eliane Hilario da Silva. A música na escola durante a ditadura militar: um ensaio. 5º SBECE. Seminário Brasileiro de Estudos Culturais e Educação. Nas contingências do espaço-tempo. Anais... Disponível em: <http://repositorio.uscs.edu.br/handle/123456789/344>. Acesso: 08 out. 2016. NOGUEIRA, Lenita Waldige Mendes. Música em Campinas nos últimos anos do Império. Campinas: Editora da Unicamp, CMU, 2001.

PESSANHA, Eurize Caldas; DANIEL, Maria Emília Borges; MENEGAZZO, Maria Adélia. Da história das disciplinas escolares à história da cultura escolar: uma trajetória de pesquisa. Revista Brasileira de Educaçáo, set/out/nov/dez 2004, no 27. Associação Nacional de Pós- Graduação e Pesquisa em Educação, São Paulo, p 57-69. Disponível em <http://www.scielo.br/pdf/rbedu/n27/n27a04.pdf>. Acesso: 03 mai.2012 
SKIDMORE, Thomas E. Brasil: de Castelo a Tancredo, 1964-1985. 7. ed. Rio de Janeiro: Paz e Terra, 1988.

SAVIANI, Dermeval. Educaçáo: do senso comum à consciência filosófica. São Paulo: Cortez Editora / Autores Associados, 1982.

SOUZA, Fernando Prestes de; LIMA, Priscila de. Músicos negros no Brasil colonial: trajetórias individuais e ascensão social (segunda metade do século XVIII e início do XIX). Revista Vernáculo, n. 19 e 20, 2007, p. 30-66.

TINHORÃO, J. R. A Deculturação da Música Indígena Brasileira. Revista Brasileira de Cultura, no 13, 1972. Conselho federal de Cultura. Disponível em <http://www.dominiopublico.gov.br/download/texto/ me002995.pdf>. Acesso: 13 abr.2012.

WARDE, Mirian Jorge. Educação e Estrutura Social: a profissionalização em questão. São Paulo: Cortez \& Moraes, 1977.

WITTMANN, Luisa Tombini. Flautas e Maracás: música nas aldeias jesuíticas da América Portuguesa (séculos XVI e XVII). Tese (Doutorado em História) - Campinas, Departamento de História do Instituto de Filosofia e Ciências Humanas. UNICAMP, 2011. 